\title{
Influence of graphene oxide on 'in situ' preparation of nanocomposites with polyvinyl butyral
}

\author{
Jean Carlos Hoepfner ${ }^{1}$, Márcio Rodrigo Loos ${ }^{2}$, \\ Sérgio Henrique Pezzin ${ }^{1}$
}

\footnotetext{
${ }^{1}$ Center of Technological Sciences, Santa Catarina State University, Joinville, Santa Catarina, Brazil.

${ }^{2}$ Department of Physics, Santa Catarina Federal University, Blumenau, Santa Catarina, Brazil.

e-mail: hoepfner.jean@gmail.com, sergio.pezzin@udesc.br,marcio.loos@ufsc.br
}

\section{ABSTRACT}

In this work, polyvinyl butyral (PVB) nanocomposites reinforced with 0.5 to $2.5 \mathrm{wt} \%$ of graphene oxide (GO) were synthesized via 'in situ' polymerization. PVB was obtained by condensation of hydroxyl groups of polyvinyl alcohol (PVA) with butyraldehyde (BU) Thermogravimetric analyzes (TGA) showed the increase in the thermal conductivity of the nanocomposites compared to PVB. FTIR results showed the conversion of PVA to PVB, but no changes in the spectrum were observed for nanocomposites. Nuclear magnetic resonance spectroscopy $\left({ }^{1} \mathrm{H} \mathrm{NMR}\right)$ shows a change in the degree of acetalization of PVB with the presence of the nanoparticles. When the increase in the concentration of GO, a decrease in the degree of acetalization of PVB is observed. The differential scanning calorimetry (DSC), show a decrease in $\mathrm{Tg}$ values, probably caused by the change of degree of acetalization. The results of the Raman spectroscopy analysis show upshift in the $\mathrm{G}$ band up to $20 \mathrm{~cm}^{-1}$, associated with the presence of van der Walls interaction between the GO and PVB and the mechanical compression phenomena of the GO nanoparticles are compressed in the 'bulk' of polymer. Thus, it was observed that the 'in situ' polymerization process contributed to the formation of a colloid between GO and water used as solvent in the synthesis. The formation of this colloid helped to improve the interfacial interaction between GO and PVB. However, the presence of GO also contributed to change the degree of acetalization of PVB, as it decreased the condensation of some hydroxyl groups of the precursor PVA degree of acetalization.

Keywords: polyvinyl butyral, graphene oxide, nanocomposites.

\section{INTRODUCTION}

Polyvinyl butyral (PVB) it is an important resin product that is commonly employed as the adhesive layer of laminated glass in vehicles and house windows. Their transparency combined with mechanical strength, flexibility and adhesiveness to metals our glass and resistance to weathering (rain, humidity, heat) [1,2].

PVB is a random copolymer of vinyl alcohol, vinyl acetate and vinyl butyral obtained by the condensation reaction of polyvinylalcohol (PVA) with butyraldehyde (BU) in acid medium. The final balance of hydroxyl groups and acetals rings will depend on the reaction conditions of the synthesis, and the relationship between these groups can produce a copolymer with varying properties in mechanical strength, permeability and thermal characteristics [3]. Figure 1 shows the chemical structure of PVB.

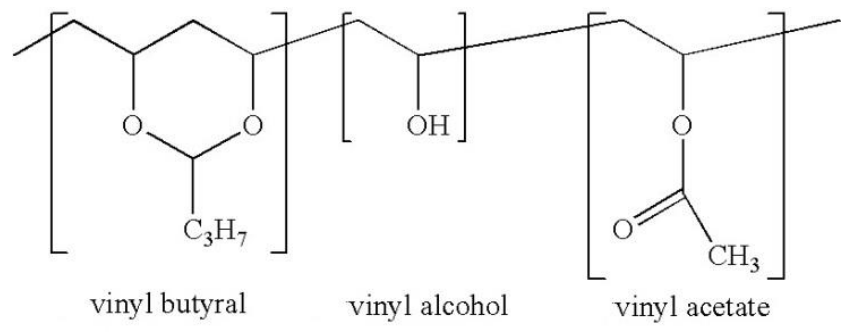

Figure 1: Chemical structure of PVB. 
Graphene oxide (GO), consisting of a 'decorated' graphene sheet with various oxygen groups, as carboxylic acids, hydroxyls and epoxy rings [4,5]. The adhesive characteristic of PVB also makes it a good candidate in the manufacture of nanocomposites reinforced with GO. However, it is known that the intermolecular interactions (van der Waals interactions) are responsible for the formation of nanoparticles agglomerates. Another difficulty is the appropriate interaction between GO and the polymeric matrix [6].

PVB has been used as a polymer matrix for carbon nanotubes to make nanocomposites with improved thermal and electrical properties [7], but there are few studies in the literature reporting PVB/graphene nanocomposites. Haijan et al. [8] have synthesized PVB via condensation of PVA in aqueous solution with BU, achieving a degree of acetalization $85 \mathrm{~mol} \%$. The nanocomposites with 0.1 to $0.6 \mathrm{wt} \%$ of graphene prepared by solution blending, showed increases in mechanical properties and thermal stability, when compared with neat PVB. Some authors prepare PVB/GO nanofibers for the production of highly sensitive sensors for determination of $\mathrm{Cu}$ (III) in water. The authors found that the sensors prepared had a higher sensitivity to those commonly used [9]. Recently, researchers prepared PVB nanocomposites with graphene functionalized by Hayldale plasma process with the objective and preparing a protective layer against corrosion in metals. According to the authors, the nanocomposites prepared by the dip-coating method had an improvement in the corrosive barrier properties due to a homegeneous dispersion and interaction of these graphenes with the PVB [10].

In this work, the interfacial interaction between GO and PVB was studied by Raman spectroscopy, DSC and TGA analysis. and correlated with the values of degree of acetalization calculated by ${ }^{1} \mathrm{H}$ NMR. It was observed that the presence of GO altered the chemical composition of PVB and influenced the interfacial interaction between GO and PVB.

\section{MATERIAS AND METHODS}

\subsection{Materials}

For the preparation of GO were used graphite and was purchased from Labsynth, Rio de Janeiro, Brazil , with particle size $<45 \mu \mathrm{m}, 98 \%$ purity and $1.0 \%$ ash content. PVA with a molecular weight of $85.300 \mathrm{~g} \mathrm{~mol}^{-1}$ was provided by Vetec Chemistry, Rio de Janeiro, Brazil and butyraldehyde (BU) $98 \%$ by Sigma-Aldrich, St Louis, USA. Sulfuric acid 98\% (Cinética), nitric acid 65\% (Merck), hydrochloric acid 37\% (Cinética), glacial acetic acid (Cinética), sodium lauryl sulphate (Cinética), sodium nitrate (Synth), potassium permanganate (Synth) and 35\% hydrogen peroxide (Cinética) were used without prior treatments

\subsection{Methods}

\subsubsection{Synthesis of graphene oxide}

For synthesis of GO from graphite using an adaptation of the Hummers method, according to another study from our research group [11].

\subsubsection{Synthesis of nanocomposites}

GO were dispersed by sonication (Sonics $750 \mathrm{~W}$ ) in $50 \mathrm{~mL}$ of deionized water for 15 minutes. To this dispersion $14 \mathrm{~g}$ of PVA, $10 \mathrm{~mL}$ of $\mathrm{BU}, 0.21 \mathrm{~g}$ of sodium lauryl sulfate, $140 \mathrm{~mL}$ of acetic acid, $90 \mathrm{~mL}$ water and a few drops of sulfuric acid were added. The system was kept in mechanical stirring in a ultrasonic bath at 10 ${ }^{\circ} \mathrm{C}$ for 120 minutes and then at $70{ }^{\circ} \mathrm{C}$ for 90 minutes. At the end of the reaction, water was added to precipitate the polymer. The polymer was filtered and washed with water and a solution of $\mathrm{NaOH} 1 \mathrm{~mol} \mathrm{~L}^{-1}$ up to $\mathrm{pH}$ 7. The polymer was then dried in an oven at $50{ }^{\circ} \mathrm{C}$ until constant weight. We prepared nanocomposites with concentrations of $0.5 ; 1.0 ; 2,5 \mathrm{wt} \%$. After this the nanocomposites were pressed in a hydraulic press under pressure of 2 ton for 2 minutes at $160{ }^{\circ} \mathrm{C}$ and them cooled for 7 minutes. The nanocomposite samples were called PVB/GO 0.5; PVB/GO 1.0; PVB/GO 2.5.

\subsection{Characterizations}

GO were characterized by Raman spectroscopy (Wintec, argon laser, $\lambda=532 \mathrm{~nm}$ ). The ${ }^{1} \mathrm{H}$ NMR spectra of the PVB and nanocomposites were recorded using $400 \mathrm{MHz}$ Bruker Advanced in DMSO-d6 without internal standard. Fourier transform infrared spectroscopy (FTIR) spectra for PVA, PVB and nanocomposites were collected with a Perkin Elmer Spectrum One B in the range of 4000 to $600 \mathrm{~cm}^{-1}$, using resolution of 4 
$\mathrm{cm}^{-1}$ and 32 scans. Differential Scanning Calorimetry (DSC) analyses were conducted in a DSC NETZSCH DSC $200 \mathrm{~F} 3$ from room temperature to $250{ }^{\circ} \mathrm{C}$ at $10^{\circ} \mathrm{C} / \mathrm{min}$ under nitrogen atmosphere. The thermal stability of the nanocomposites was evaluated by the thermogravimetric analysis (TGA) in the NETZSCH STA 449C equipment, using a heating rate of $10{ }^{\circ} \mathrm{C} \mathrm{min}^{-1}$ from 25 to $600{ }^{\circ} \mathrm{C}$ under a nitrogen atmosphere. TGA analysis for $\mathrm{GO}$ was evaluated in the same equipament but, using a heating from 25 to $1000{ }^{\circ} \mathrm{C}$ under nitrogen atmosphere. The nanocomposites were characterized by Raman spectroscopy was performed using a BRUKER equipment with $1064 \mathrm{~nm}$ wavelength laser from $\mathrm{Ne} / \mathrm{Y}$.

\section{RESULTS AND DISCUSSIONS}

\subsection{Characterization of Nanocomposites}

Figure 2 shows ${ }^{1} \mathrm{H}$ NMR spectra for PVB and nanocomposites. It is observed that the spectra of nanocomposite were very similar to that the PVB, not being observed the presence of new peaks or displacements.

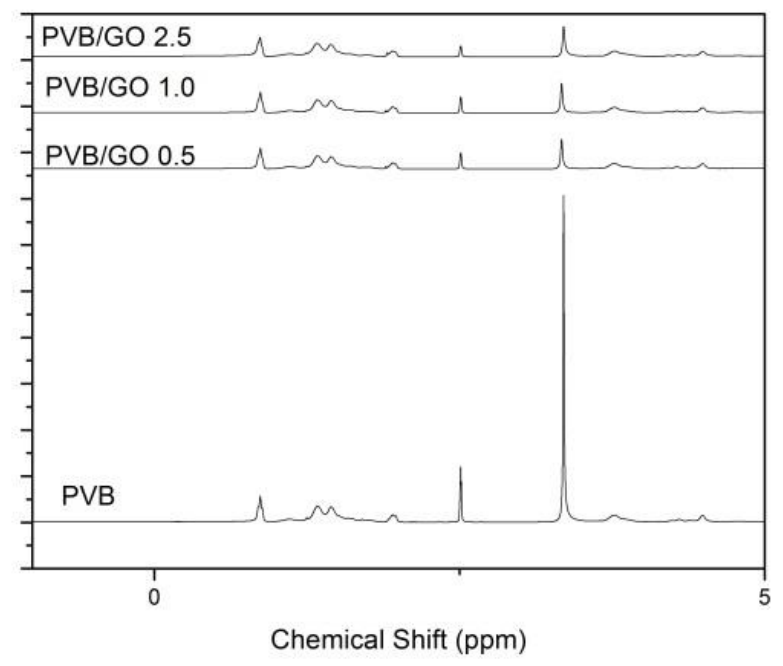

Figure 2: ${ }^{1} \mathrm{H}$ NMR spectra to PVB and nanocomposites

Figure 6 shows the H1 NMR spectra for the PVB and nanocomposites, and by means of equation (1) the values of degree of acetalization (DA) were calculated: [1]

$$
(D A)=\frac{2}{\frac{\left(A C H_{2}\right)}{\left(A C H_{3}\right)}-6}
$$

The degree of acetalization (DA) represents the molar percentage between the butyral groups $(\%$ of VB). For this work, the degree of acetalization was $65 \mathrm{~mol} \%$. Other researchers obtained similar values for the degree of acetalization. The peaks at 4.4 and $4.7 \mathrm{ppm}$ werebased on dioxymethine of acetal ring in PVB. The peaks found at 1.8 and 0.75 were due to methylene and methyl protons in the vinyl butyral ring, respectively [1]. Saravanan et al. [12] synthesized the PVB with different DA, obtaining values of 50, 75 and 90 mol\%. In another study the researchers obtained DA ranging from 36 to 96 mol\% [2]. Table 1 shows the values of the DA are similar, being the only exception the sample PVB/GO 2.5, which had a decrease in value. Since GO has a large amount of hydroxyls covalently attached to its structure, they may have influenced in the condensation of PVA with BU, causing BU prefer to react with the hydroxyls of GO than PVA. In the case of PVB / GO 0.5, as the GO concentration is lower, BU reacts preferentially with the hydroxyls of PVA. In the case of $\mathrm{PVB} / \mathrm{GO} 1.0$, the value of the degree of acetalization is practically the same as the PVB and therefore indicates that in this case the GO did not influence the condensation of the PVA by the BU molecules. 
Table 1: Values of degree of acetalization for PVB and nanocomposites

\begin{tabular}{c|c}
\hline SAMPLES & $\begin{array}{c}\text { Degree of acetalization } \\
\text { (mol\%) }\end{array}$ \\
\hline PVB & 65 \\
\hline PVB/GO 0.5 & 60 \\
\hline PVB/GO 1.0 & 68 \\
\hline PVB/GO 2.5 & 51 \\
\hline
\end{tabular}

Figure 3 show the TGA analysis of PVB and nanocomposites. It is observed that for PVB there are three termal decompositon steps. T. The first thermal decomposition step at $330{ }^{\circ} \mathrm{C}$ refers to the elimination of the side groups (alcohol and acetal groups). The second thermal decomposition step at $380{ }^{\circ} \mathrm{C}$ refers to the elimination of the remainder of the acetal groups and the last termal decomposition step at $450{ }^{\circ} \mathrm{C}$ is related to the cleavage of the polymer chain [13].

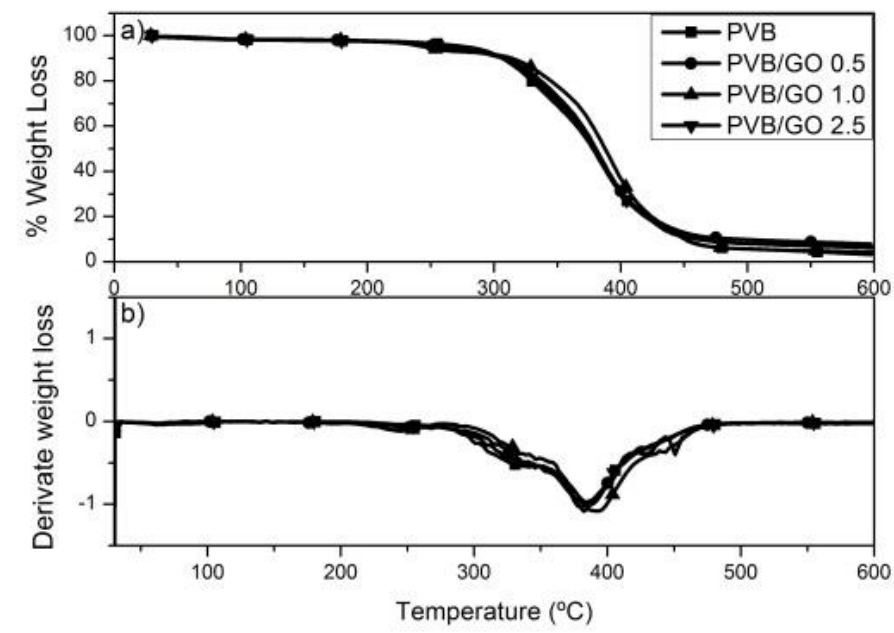

Figure 3: a) TGA analysis and b) derivated of TGA for PVB and nanocomposites

For nanocomposites, a thermal decompositon step is observed around $250{ }^{\circ} \mathrm{C}$. This step of degradation may be associated with the elimination of the first alcohol groups, because as observed in the ${ }^{1} \mathrm{H}$ NMR results, a part of the PVA could not be converted to PVB. Another thermal decomposition temperature of about $330{ }^{\circ} \mathrm{C}$ is observed indicating the decomposition of acetal and alcohol groups. It is also observed a shoulder around $450{ }^{\circ} \mathrm{C}$ for PVB and all samples that also indicate the polymer chain breakage.

Table 2 shows the values of $T_{\text {onset }}$ and $T_{\max }$ for PVB and nanocomposites. It is noted that there were no significant increases for these two temperatures, except for the PVB/GO 1.0 sample which had an increase of $17^{\circ} \mathrm{C}$ for the Tonset and $10^{\circ} \mathrm{C}$ for the Tmax, compared to pure PVB. These increases can mean an interaction between GO and PVB. [14]. However, it is known that carbon nanoparticles are excellent thermal conductors. Thus, some authors state that increases in $T_{\text {onset }}$ and $T_{\max }$, would be attributed only to this phenomenon and not directly the dispersion of these nanoparticles in the matrix [15].

Table 2: Values of Tonset and Tmax for PVB and nanocomposites

\begin{tabular}{c|c|c}
\hline SAMPLES & $\boldsymbol{T}_{\text {onset }}\left({ }^{\circ} \mathbf{C}\right)$ & $\boldsymbol{T}_{\max }\left({ }^{\circ} \mathbf{C}\right)$ \\
\hline PVB & 323 & 383 \\
\hline PVB/GO 0.5 & 327 & 382 \\
\hline PVB/GO 1.0 & 340 & 393 \\
\hline PVB/GO 2.5 & 320 & 383 \\
\hline
\end{tabular}


Figure 4 shows the $T g$ values for the PVB and nanocomposite samples. It is observed that the $T g$ of PVB was at $72^{\circ} \mathrm{C}$, similar to that obtained in other works $[16,17]$. For the nanocomposites, a changed of $\mathrm{Tg}$ was observed in all the samples, However, this change is not considered significant in nanocomposites made from amorphous polymers and carbon nanoparticles [18].

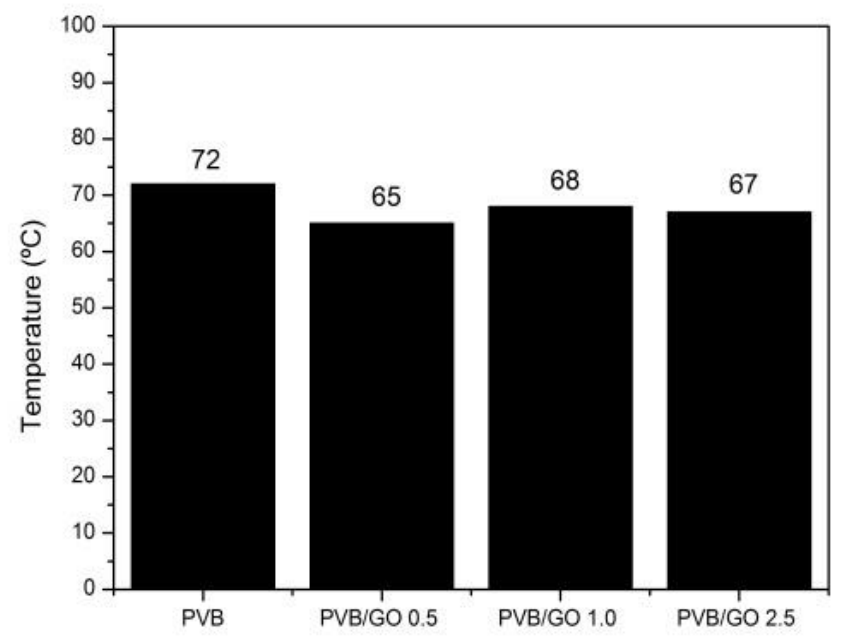

Figure 4: Values of a) Tg obtained in the transition inflection of b) DSC curves for the second heating.

Figure 5 compare the FTIR spectra of PVA with the PVB and nanocomposites. It is observed that the PVB spectrum still has some bands related to PVA, as the $\mathrm{OH}$ stretch at $3490 \mathrm{~cm}^{-1}$. However, for PVB a decrease in intensity of this band, characterizing that part of the hydroxyl groups of the PVA was condensed into acetals and butyrals groups. The bands 1050 and $1150 \mathrm{~cm}^{-1}$ correspond to symmetric and asymmetric stretching of the $\mathrm{C}-\mathrm{C}$ vibrations present in the butyral ring. The band at $1740 \mathrm{~cm}^{-1}$ is attributed to the presence of acetal groups, confirming the conversion of PVA to PVB [2,8]. The spectra observed for nanocomposites are similar to $\mathrm{PVB}$, indicating that were no changes in the chemical composition of nanocomposites with the addition of GO.

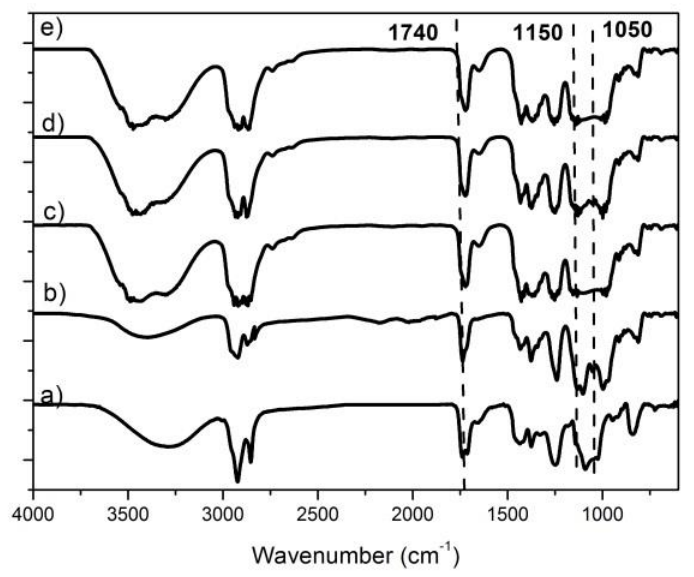

Figura 5: FTIR spectra for a) PVA; b) PVB; c) PVB/GO 0.5; d) PVB/GO 1.0 and e) PVB/GO 2.5.

Figure 6 shows the Raman spectrum of PVB in which four bands are observed. At $1441 \mathrm{~cm}^{-1}$, relative to the $\mathrm{C}-\mathrm{O}-\mathrm{H}$ bond and shows the spectrum of GO-reinforced nanocomposites. 


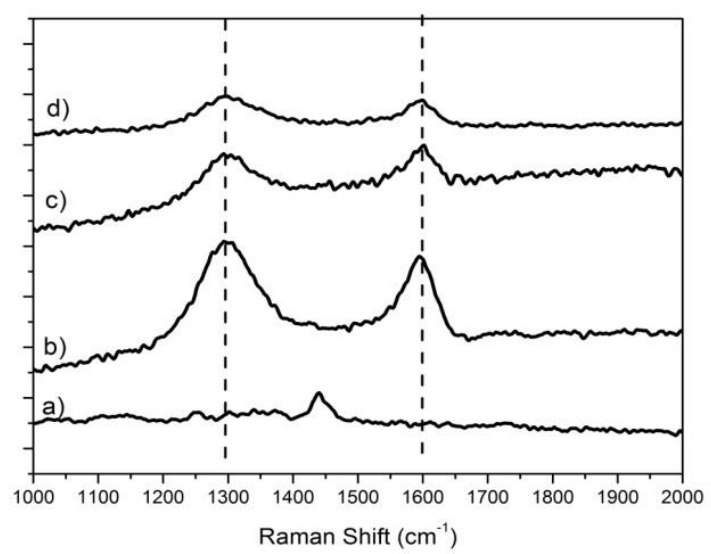

Figura 6: Raman spectra for a) PVB; b) PVB/GO 0.5; c) PVB/GO 1.0 and d) PVB/GO 2.5.

Table 3 shows the values for the D and G bands of the nanocomposites. It is observed that the values of wavenumbers of the D and $\mathrm{G}$ bands are displaced in relation to the values obtained only for neat GO. It is observed downshifts in $\mathrm{D}$ band and upshitf in $\mathrm{G}$ band for the nanocomposites.

Table 3: Raman Shifit of $\mathrm{D}$ and $\mathrm{G}$ bands, $\mathrm{I}_{\mathrm{D}} / \mathrm{I}_{\mathrm{G}}$ for $\mathrm{GO}$ and nanocomposites.

\begin{tabular}{c|c|c|c}
\hline SAMPLES & D Band $\left(\mathbf{c m}^{-1}\right)$ & G band $\left(\mathbf{c m}^{-1}\right)$ & $\mathbf{I}_{\mathbf{D}} / \mathbf{l}_{\mathbf{G}}$ \\
\hline GO & 1345 & 1584 & 0,85 \\
\hline PVB & --- & -- & -- \\
\hline PVB/GO 0.5 & 1293 & 1595 & 0,81 \\
\hline PVB/GO 1.0 & 1301 & 1601 & 0,81 \\
\hline PVB/GO 2.5 & 1297 & 1599 & 0,81 \\
\hline
\end{tabular}

The samples showed Raman displacements of upshift to $20 \mathrm{~cm}^{-1}$ for the $\mathrm{G}$ band. This shift $\mathrm{G}$ band to larger wavenumbers relative to the nanoparticles could indicate interactions between the polymer matrix and the nanoparticle or the increase of nanoparticles with $\mathrm{sp}^{3}$ hybridization caused by the functionalization and adhesion of the polymers in the nanoparticles [19,20]. Table 3 also shows that the intensity ratio of the $I_{D} / I_{G}$ bands of the nanocomposites is similar to that observed in the nanoparticles, which suggests that there is no effect of the degree of graphitization of the nanoparticles [19]. However, Yang et al. [19] did a study using Raman spectroscopy to evaluate the interfacial interactions between carbon nanotubes (CNT) and polystyrene (PS). According to the authors, the G-band displacements indicate that the mechanical compression was transferred from PS to CNT. The same authors indicated that the upshift may be related to van der Walls effects between CNT and PS.

Thus, as no changes in the FTIR spectrum (Figure 5) are observed which indicate that the upshift observed in the Raman spectrum is of a chemical bond, possibly this observed displacement is due to the mechanical compression phenomenon that the nanoparticles suffer when immersed in a liquid or polymer. The hydrostatic pressure induces upshifts of Raman bands of GO. Wood et al. [21] reported that the pressureinduced shifts of various single walled carbon nanotubes (SWCNT) bands occurred when SWCNTs were embedded into liquid or when pressure was applied using by a diamond anvil cell (DAC). It has been confirmed that the peak shifts are induced by compressive forces imposed by the liquid on the SWCNT.

\section{CONCLUSIONS}

The results os Raman spectroscopy showed that the 'in situ' polymerization process was efficient for improving interfacial interaction between PVB and GO. However, the presence of GO during the polymerization process eventually changed the values of degree of a acetalization as observed by $\mathrm{H}^{1}$ NMR. Probably the 
presence of the GO affected the condensation of the hydroxyl groups of the PVA, mainly for the sample PVB / GO 2.5, since with higher concentration of GO, there was a greater presence of free hydroxyl groups in this nanoparticle that suffered condensation by the BU. This process resulted in a lower value of degree of acetalization for this sample possibly because BU was consumed by condensing the hydroxyl groups of the GO and not the PVA for the formation of the PVB.

\section{ACKNOWLEDGMENTS}

This work was supported by State University of Santa Catarina (UDESC) who provides of the facilities, University of Vale do Paraíba (UNIVAP) for Raman spectroscopy analysis, and by Foundation for Protection of Research in Santa Catarina (FAPESC) who provided the PhD and financial resources scholarship to carry out this research.

\section{BIBLIOGRAPHY}

[1] CHA, Y-J., LEE, C-H., CHOE, S., 'Morphology and mechanical properties of Nylon 6 toughened with waste poly(vinyl butyral) film', Journal Applied Polymer Science, v. 67, n.9, pp.1531-1540, Feb. 1998.

[2] FERNANDEZ, M. D., FERNANDÉZ, M. J., HOCES, P., 'Synthesis of poly(vinyl butyral)s in homogeneous phase and their thermal properties', Journal of Applied Polymer Science, v. 5, pp. 5007-5017, Sep. 2006.

[3] RAGHAVENDRACHAR, P., CHANDA, M., 'A kinetic model for heterogeneous acetalization of poly(vinyl alcohol)', European Polymer Journal, v. 20, pp. 257-263, Dec. 1984.

[4] HUMMERS, W. S., OFFEMAN, R. E., 'Preparation of graphitic oxide', Journal of the American Chemical Society, v. 80, pp. 1339, Mar.1958.

[5] PARK, S., RUOFF, R. S., 'Chemical methods for the production of graphenes', Nature nanotechnology, v. 4, n.4, pp 217-224, Mar. 2009.

[6] JIN, F. L., PARK, S. J. 'A review of the preparation and properties of carbon nanotubes-reinforced polymer composites'. Carbon letters, v.12, n.2, pp. 57-69, Mar. 2011.

[7] CHARITIDIS, C. A., KOUMOULOS, E. P., GIORCELLI, M., et al., 'Nanomechanical and tribological properties of carbon nanotube/polyvinyl butyral composites', Polymer Composites, v. 31, n. 11, p. 1950-1960, Aug. 2013.

[8] HAIJAN, M., REISI, M. R., KOOHMAREH, A. L., et al., 'Preparation and characterization of Polyvinylbutyral/Graphene Nanocomposite', Journal Polymer Research, v. 19, Sep. 2012.

[9] DING, L., QIN, J., 'Dimethyl phosphite sulfone method production PVB'. Contemp. Chemistry Industrial, v. 37, p 453-455, 2008.

[10] CHAUDHRY, A. U., MITTAL, V., MISHRA, B., 'Impedance response of nanocomposite coatings comprising of polyvinyl butyral and Haydale's plasma processed graphene', Progress in Organic Coatings, v. 110, pp 97-103, May 2017.

[11] SILVA, D. D., SANTOS, W. F., PEZZIN, S. H., 'Epoxy resin nanocomposites with reinforcements produced from natural graphite', Matéria, v.18, n. 2, pp 1260-1272, May 2013.

[12] SARAVANAN, S., GOWDA, K. A., VARMAN, K. A., et al., 'In-situ synthesized poly (vinyl butyral)/MMT-clay nanocomposites: The role of degree of acetalization and clay content on thermal, mechanical and permeability properties of PVB matrix', Composites Science and Technology, v. 117, p. 417-427. Jul. 2015 .

[13] LIAU, L. C. K., YANG, T. C. K., VISWANATH, D. S., 'Reaction athways and kinetic-analysis of PVB thermal-degradation using TG /FTIR' Applied Spectrosccopy, v. 50, p. 1058-1065, Aug. 1996.

[14] GRACIA-FERNANDEZ, C. A., GOMEZ-BARREIRO, S., RUIZ-SALVADOR, S., et al., 'Study of the degradation of a thermoset system using TGA and modulated TGA', Progress Organic Coating, v. 4, p.332-336, Sep. 2005.

[15] HAN, Z., FINA, A., 'Thermal conductivity of carbon nanotubes and their polymer nanocomposites: a review', Progress in polymer science, v. 36, n.7, p. 914-944, Dec. 2013.

[16] ZHOU, Z. M., DAVID, D. J., MACKNIGHT, W. J., et al., 'Synthesis Characterization and Miscibility of Polyvinyl Butyrals of Varying Vinyl Alcohol Content', Journal of Chemistry, v. 21, p. 229-238, Jan. 1997. 
[17] NAKANE, K., TAKASHI, O., NOBUO, O., 'Properties of poly(vinyl butyral)/ $\mathrm{TiO}_{2}$ nanocomposites formed by sol-gel process', Composites Part B: Engineering, v. 35, p 219-222, Oct. 2004.

[18] YAN, Y., ZHANG, J., CUI, J., et al., (2012). "Rheological, thermal, and mechanical characterizations of polystyrene/single-walled carbon nanotube composites", Colloid and Polymer Science, v.290, n.13, pp.12931300, April 2012.

[19] AMRIN, S., DESHPANDE, V. D., 'Electrical properties and conduction mechanism in carboxylfunctionalized multiwalled carbon nanotubes/poly (vinyl alcohol) composites', Journal of Materials Science, v. 51, n. 5, p 2453-2464, Jan. 2016.

[20] YANG, X., LI, L., SHANG, S., et al., "Synthesis and characterization of layer-aligned poly (vinyl alcohol)/graphene nanocomposites", Polymer, v. 51, n. 15, p. 3431-3435, May 2010.

[21] WOOD, J. R., WAGNER, H. D., "Single-wall carbon nanotubes as molecular pressure sensors", Applied Physics Letters, v. 76, n.20, pp. 2883-2885, Mar. 2000.

\section{ORCID}

Jean Carlos Hoepfner https://orcid.org/0000-0003-0933-8254

Sérgio Henrique Pezzin https://orcid.org/0000-0002-5667-1968

Márcio Rodrigo Loos Não informado 